\title{
Alternative Representations of Women in the News
}

\author{
NGOs as a Source for Gender Transformation
}

\author{
JiLL JOHANNESSEN
}

Women liberation is not only a struggle to gain economic and political power and equality, but a symbolic struggle over the cultural definition of femininity and masculinity. Such struggles are fought in the realm of mass communication entailing both those who like to challenge dominating definitions and those yearning to maintain the old and predictable dichotomies (van Zoonen 1994; 5). In this paper, I am directing the attention to new symbolic codes created by challenging groups that are expressed through public discourse ${ }^{1}$. I aim to grasp the flexibility of news discourse in constructing possible alternative and maybe challenging definitions of gender in addition to mainstream representations of women, which in turn are responsible for engendering positions for its readers. The mass media are only one arena for public discourse, but they are the central one for social movements, because they are the only sites that provide a potentially shared public discourse (Gamson 1995; 85). The news media in particular play a crucial role for the wider dissemination and approval of new ideas and values and by framing events and issues significant for a woman movement.

The media has a role to play in the struggle for gender transformation and in saluting the achievements of women in society, in order to inspire others (Tanzania Gender Network Programme, 1997).

In contrast to most feminist research I have chosen to address women liberation as a cultural struggle within a development context focusing upon the cultural underpinnings of communication that might restrict or channel development and social change. The media is perceived as a major source of definitions and images of social reality, including representations of women and definitions of femininity. Thus, the media is also the place where the changing culture and the values of societies and groups are constructed and most visibly expressed. Tanzania makes an interesting case study in this respect. As in several other African countries, external and internal pressure and the struggle towards development have lead Tanzania to open up for democratic and economic reforms. From African socialism as guidelines in the sixties, Tanzania has changed its course to a multiparty system and marked economy in the mid-eighties. The political watershed facing Tanzania has created new opportunities for women to organize, articulate and express themselves. In addition, a new focus upon NGOs to hold an important role in development and civil society, from both donors and governments, makes it more legitimate for women/gender activists to fight for women's rights and emancipation. In sum, these 
changes have lead to a mushrooming of women/gender NGOs, which are crucial for a woman's movement to emerge. The new political-economic framework has also made it possible for private media to operate which opens up for both new possibilities and risks for a woman's movement. On one hand, it has lead to an explosion of mass mediated communication and a more open and independent media system, which gives the mass media the possibility to take a more active role in the struggle for gender transformation. On the other hand, liberalization and commercialization of the media serves as a recurring explanation for increased and widespread portrayal of women as objects of male pleasure and violence in Tanzania (Mtambalike 1996; 135). The political-economic transformation has also resulted in new social problems and tensions in the society, between traditional and modern values and ways of life with important bearing on gender notions and ideas. In this new landscape the media is becoming an important cultural agent and an arena for conflicts and contestation. As an agent for change the media can challenge dominant discourse by providing the society with alternative representations of women, new gender ideas and identities, values and ways of living that crosscut earlier traditions and beliefs. The media can also reinforce traditional gender definitions and cultural patterns and thereby legitimate, justify and preserve dominant ideology of gender.

Women liberation is seen to have wider implications for development, which is supported by recent approaches to development that gives more attention to human development, human rights and grassroots participation (Melkote 1991). Along with this movement follows an assumption that development cannot occur without integrating women as active participants in development processes. This calls for gender transformation in society that replace traditional attitudes against women as subordinate and incapable creatures with gender notions promoting equality and positive attitudes towards women as capable of making a living, taking decisions, and participating in all areas of life and society. A key question is whether women are portrayed as subjects taking an active role in their society and able to influence their own life situation or become objects of other people's actions, which inscribes a 'reader position' of women to be coordinated and objectified.

A common notion in feminist media and development studies has been that constant under-representation of women and women's issues in the media or portraying them in a negative and stereotype manner work as a barrier to women's participation, empowerment and development. I take another point of departure in which I focus on alternative representations of women that can open up new thoughts, perceptions, and actions. At the same time, I am trying to keep a critical outlook in order to identify oppressive gender structures in the news discourse. This standpoint has several implications for this paper. First, it has guided me to study the news coverage of a key event in a woman's movement in Tanzania conducted by a prominent woman non-governmental organization. Second, it has lead to a post-structuralist orientation, which provides a focus upon the media as a site of conflict and contestation in which the definition of gender is subjected to continuos discursive struggle and negotiation. Finally, the nature of this study turned my attention to interpretative forms of inquires that can account for the contradictions in the construction of gender in news and the ambiguous process of meaning production. On the following pages, I discuss the theoretical orientation and implications for this paper, and provide an outline of the analytical model used to analyze media texts. Then, I will return to explore issues of gender representations through a concrete case study consisting of news coverage of a debate on gender violence and sexual abuse organized by a prominent woman NGO. 


\section{Gender as Constructed in Media Discourse}

I argue that a post-structuralist orientation in feminist media research can help to improve conceptualizing how gender might be articulated in media discourses. Feminist poststructuralism introduced a perspective on gender as part of an ongoing process, never finished, stable or true often constituted in paradoxical ways (van Zoonen 1994; 33). This view opens up to see gender as a cultural construction or as constructed in discursive practices. Gender then is seen to be an intrinsic part of culture - loosely defined as the production of meaning - and is subjected to continuos discursive struggle and negotiation (van Zoonen 1994; 33). Within this perspective media are seen as sites of conflict and contestation, accommodating, modifying, reconstructing and producing as well as disciplining contradictory cultural definitions of femininity. This view opens up for multiple ideological positions, which position the individual subject in heterogeneous, overlaying and competing ways (Ang/Hermes 1996; 334). The emphasis of post-structuralism on the multiplicity of discourse allows for oppositional discourses to develop. A central point therefore is that the disciplinary power of discourse prescribing and restricting gender identities and experiences can be resisted and subverted. I therefore find a post-structuralist orientation to carry a liberal element, which is crucial in a cultural struggle of women liberation and explaining social change in general. Within this perspective woman/gender NGOs can be viewed as "communities of discourse" engaged in the enunciation of new cultural codes that often contest dominant cultural codes and representations by articulating new ideas, values, and frames of interpretations (Lichterman 1992 in Taylor/Whittier 1995).

Still, central to post-structuralism is to analyze gender as embedded in existing power formations in society, which influences the representations and perception of women. The access and power to engage in the processes of reality defining is not equally distributed, but intricately linked to variables such as gender, class, ethnic, political-economic and international relations. This means that post-structuralism not only stress the multiplicity of discourse reflecting the contradictive and ambiguous process of meaning production, but also prompts a critical perspective on discursive practices highlighting gender ideology and power relations. Discourse is also itself a form of power, since both the process of discourse (the symbolic interaction) and the product of discourse (i.e. gender definitions) limit the possibilities of interpretation and privilege certain meanings above others (van Zoonen 1994; 39). As van Zoonen points out, the power of discourse lies not only in its capacity to define what is a social problem, but also in its prescriptions of how an issue should be understood, the legitimate views on it, the legitimacy and deviance of the actors involved, the appropriateness of certain acts etc. (van Zoonen 1994; 40).

Post-structural feminist theory has adopted a profound sense of gender skepticism, and thereby eradicating any pre-given guarantee for female unity, which has made feminist activist uneasy by the political implications of post-structuralism. This position erodes the rationale of articulating universal and absolute demands for 'political correctness', truths and solutions, but not necessarily involve relativist political retreat. Rather it is an acknowledgment that in order to confront 'sexism in all its endless variety and monotonous similarity' a more flexible and pragmatic form of criticism might be more effective than one based upon pre-defined truths (Fraser \& Nicholson 1990 in Ang/Hermes 1996; 342). As such feminist post-structuralism can be seen a critical reaction to the normative and moralist absolutism in earlier feminist traditions and approaches. Acknowledging the media's role as constructing female representations rather than reflect and locate the true image of women doesn't mean that we have to accept those constructions 
(Leonor Camauer 2001; 10). In order to formulate a comprehensive cultural critique it is an important task to analyze how gender representations are constructed, reconstructed and contested in media discourses, for instance in news and genre conventions. The media have a responsibility to report upon a multitude of representations, issues and concerns contributing to a better understanding of women's lives and that empower women to take an active role in the social transformation of their societies.

\section{Analytical Model}

Discourse analysis of media entails different levels and dimensions in texts that might form a consistent pattern of discursive features that signal various and even contradictory underlying meanings, opinions and ideological positions (van Dijk 1991). I have chosen narrative analysis as starting point for an ideological analysis rather than a strict linguistic or semiotic approach. Narrative analysis is not limited to dramatic narrative programs, but also applicable to other genres such as news. Narrative analysis is based upon the notion that every story is told by 'someone' and in particular ways to whom and for whose benefit the story is told (Allen 1992; 113). It can help to explain how the transmission of news and news conventions are crucial for the ways media handles social tensions and contradictions, and how the structural and functional logic of text development naturalize a sequence of events (White 1991; 173).

A common distinction in narrative analysis is between story and discourse (Kozloff $1991 ; 67$, Chatman 1978; 19). The story is occupied with the question what in the narrative (what happens to whom) consisting of two major elements; events (actions or happenings) and existents (news actors and setting). The discourse is how the story is told, which includes the means by which the content is communicated. The discourse is said to 'state' the story. As illustrated in figure 1, these statements are of two kinds - process and stasis. Process statements are in the mode of DO or HAPPEN - as abstract expressional categories - either in form of recounting or enacting an event. Stasis statement is the mode of IS, either in form of exposing or presenting. We can see from the model below that events build upon process statements according to whether someone did something or something happen that either way bring a change of state. I have added to the model that an action can be carried out by a male or a female agent, driven by selfinterest or for the social good (family, community or society at large) with fortunate or fatal consequences for those involved ${ }^{2}$.

\section{Figure 1. Elements of a Narrative Grid and Gender Dichotomy}

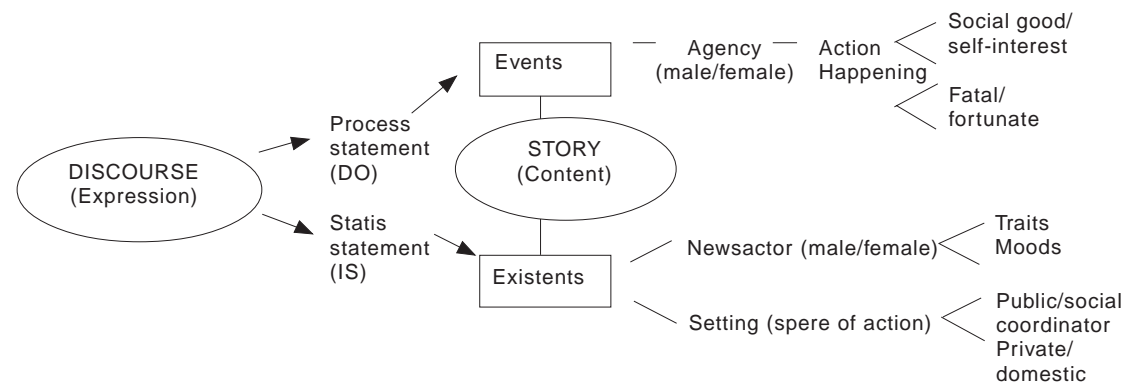

Source: Seymour Chatman (1983): Story and Discourse. Narrative Structure in Fiction and Film. 
Stasis statement points to whether something simply exist in the story, which includes news actors and setting. The importance of a news actor can be seen to the extent he/she takes or is affected by significant actions or happenings. I have integrated into the model a classification of 'spheres of action', divided into the private/domestic sphere and the public/social coordinating sphere. If the agent or narrative subject recurrently appears in form of a male and the existent or narrative object takes shape of a female it is a clear indication that a man is thought to be active and enacting upon events, while a woman is seen as passive and subjected to other peoples actions and decisions. One implication is that men are associated with the sphere of wider social coordination while women occupy the sub-units being coordinated with possible disempowering effects for women.

Discursive devices in the transmission of news, which might support or undercut the thematic, might concern order and selection. Different news genres have different conventions of the presence/absence of the journalist. Most news reports are at the negative pole of journalist-presence trying to appear as objective as possible. We hear a voice speaking of events or news actors, but its owner reminds hidden in the discursive shadows. Such expression implies interpretative devices or mediator, which include backgrounding and foregrounding of elements of various degrees of importance, and presuppositions (Chatman, 1978; 197). In news an interpreting person of events, issues or agents can appear in form of an informant or authority. Altogether, I attempt to get a better understanding of powerful spoken and unspoken cultural messages subsumed by 'alternative' news by addressing both the thematic and structure of news.

\section{Case Study: Gender Violence \& Sexual Abuse}

Gender-based violence and sexual abuse used to be a taboo in Tanzania and the victims would suffer in silence while the offenders would go free. However, the last decade featured by liberalization and commercialization of the media and increasing pressure from feminist groups stories about rape and sexual abuse against women and children have become a daily event in the Tanzanian press $^{3}$. On one hand, it is of crucial importance for a woman's movement that these stories are exposed to the public. On the other hand, there is also a danger that women are reduced to victims of men's actions sitting on the sideline in discussions influencing their lives. On this background, I have chosen an event-oriented case study consisting of news coverage of a prominent woman non-governmental organization concentrating their efforts against gender-based violence and sexual offenses.

Tanzania Media Women Association (TAMWA) is in the forefront of women's struggle for liberation in Tanzania. TAMWA stands out by their continuous efforts to put violence against women and children on the political agenda as well as using the media as a tool for sensitization purposes. As such TAMWA is an important vehicle producing and carrying the message of an emerging woman movement in Tanzania. However, the chosen event is just one moment in the formation of a woman movement. The following case study consists of newspaper coverage of a debate on gender violence and sexual harassment organized by TAMWA, which they held for the Members of Parliament (MPs) in Dodoma, Tanzania, July 26th 1997. TAMWA wanted to sensitize the MPs on the magnitude of gender-based violence and child abuse in Tanzania, and to win support of the legislators to repeal or amend laws that discriminate or deny women and children of their basic human rights. The Symposium resulted in a dialog among the policy makers in society, which subsequently contributed to the new "Sexual Offences Special Provision Bill 1998". 
The TAMWA Symposium attracted many journalists and received extensive media coverage. 12 newspapers were involved in covering the event with a total of 35 articles. For analytical purposes the articles have been divided into groups according to well-used journalistic categories. The first group of articles focuses primarily on wHAT is happening; what the debate is about, the problems, issues etc. The second category is occupied with HOw TAMWA carried out or planned to carry out the event. The third group of articles focuses on HOw to deal with the increasing incidents of rape, defilement and sodomy, measures to be taken etc. Finally, I have included a section focusing upon wHY is it happening and шном to blame.

\section{Struggle for Women's Rights is Legitimate}

Ten articles focus mainly on what the TAMWA Symposium is about and the issues involved. In terms of story and discourse the analysis shows a general pattern based upon process statements in which TAMWA is portrayed as the agent leading up to the debate on gender violence, rape and sexual harassment against women and children. TAMWA is foregrounded in the stories in headings and lead paragraphs. The positioning of TAMWA can be illustrated in the example below:

\section{Mtanzania July 271997 Editorial}

\section{TAMWA has lighted up the torch, our duty is to race it}

Yesterday for the first time in the history of our nation there were processions and later debate in Dodoma town about the practices of raping, sodomising and sexual harassment against women, male and female children which are now common in the country. The Tanzania Media Women Association (TAMWA) organized this event, which is peculiar, and it involved citizen, public institutions, international and private institutions. The problem of raping is big; therefore there is no reason for writing a lot about it. It is an issue that requires deep investigation and undoubtedly no one can object that it is necessary to fight against it by any means. It is not only that raping is an act, which is inhuman, but also it harasses and humiliates, that is why in most cases the victims end up in problems....

TAMWA's actions are seen to be driven by a motivation for the social good for the society at large, and with intended fortunate effects for women and children. This is evenmore evident anothe editorial: "The director of the Dodoma debate, Mrs. Maria Shaba should use her status and act as a hero of millions of women who are being harassed and undervalued. Maybe after the Dodoma debate, women and children harassment and raping events will decrease". Among these articles there were surprisingly many editorials and commentaries - genres that aim to be pervasive or argumentative which can be taken as an indication that the newspapers take an active role in framing the event. This is reflected on several levels in the texts. In the last paragraph the support of TAMWA is repeated directly or indirectly by inviting the Members of Parliaments (MPs) to take the issue seriously and to amend laws to accommodate stern measurement against the offenders. The authors are present in the texts using the pronoun 'we', making interpretations, judgments and generalizations that might mold beliefs in favor of women. "The habit of leaders to address in words without any implementations should 
be abandoned, otherwise it will be difficult for our nation to develop. Lastly, we insist that campaigning to eliminate the acts of raping and harassing women should continue" (Commentary: SHABA, 28/7/97). Also language and choices of vocabulary support the positive position the newspapers have taken regarding the Symposium. Rape and sexual harassment are described in negative laden terms, such as inhuman, horrible, evil acts, terrible problem, and dangerous game. There is also a tendency to place gender violence and sexual abuse within the context of women's rights as well as in relation to women's low status in society (economically, politically, and culturally). This is especially evident in two interviews with TAMWA members, which puts the Symposium into a broader context for potential readers. The TAMWA members draws upon a liberal feminist framework of human rights, basic and legal rights, and laws discriminating women in inheritance, land tenure, education, and cultural heritage. The context brings out that sexual offenses are one of many interrelated important issues for women liberation.

In contrast to editorials, commentaries, and even reader's letters, the authors in news reports are minimally present. Three news reports are covering the Symposium's objectives and issues, which record nothing beyond the speech of news actors. However, indirectly the articles support TAMWA by order and selection of sources and statements. One of the news reports stresses the magnitude of rape, sodomy, and wife battering by using TAMWA sources and source texts: 2400 WOMEN HAVE BEEN RAPED: TAMWA REVEALS IN DODOMA (HEKO, July 27 1997). Hence, the article gives precedence to TAMWA and their conceptualizations and thereby indirectly support TAMWA's efforts. Statistics and research is a form of form of generalization that also gives legitimacy to the issues.

The different levels and dimensions of the analysis form a rather coherent pattern of discursive features supporting TAMWA's objectives and fight against gender violence and abuse in both an open and direct and a more covert manner. Thus, the coverage gives legitimacy to the issue of gender violence and sexual abuse. At another level an implication of the coverage is that it contest the dominant gender dichotomy. Women are making headlines in vigor of their social status, acting as social coordinators in the public sphere who are willing to take action to influence political-legal processes to improve the lives of women and children. These representations of women crosscut traditional beliefs of women as subordinate, weak, passive and dependent, and thereby contribute to more modern and positive perception of women as able to participate in soceity and development of the country. Hence, these newspaper articles can be characterized as empowering.

\section{Bringing Private Destines to Parliament, Not Acceptable}

11 articles are concerned with how TAMWA planned to carry out or conducted the event. As the discourse turns from emphasizing WHAT to HOw, TAMWA has to share the role as the agent or textual subject with the MPs. Along with this shift the majority of the articles facilitate a negative image of TAMWA by foregrounding accusations and criticism against TAMWA's methods. To a large extent the criticism is allowed to pass uncontested. Two major issues are recurring.

The first issue concerns TAMWA's plan to bring rape victims to 'testify' before the MPs. The articles have slightly different focus, but they are all based on the same chain of events: TAMWA wants to bring rape victims to Parliament (X); MPs react with refusal to attend if TAMWA goes through with their plans (Y). As a final consequence TAMWA decides not to bring life testimonies before the MPs (Z). According to the newspapers 
MPs refused live testimonies, because it would further harass those women, which the following statement illustrates: "What jolted my mind was the proposals to parade victims of rape and defilement to testify before the MPs. Thank God this did not happen. One up for the office of the parliament, which I am told, shot down the idea. Having said that, I must acknowledge that the Symposium stirred the right reaction from MPs" (Editorial: Daily News 28/7/97). TAMWA's action then may be interpreted as an act of selfinterest with possible fatal consequences for those female victims involved, while MPs contra action is seen as for the social good and with fortunate effects. An implication to draw from this is that it is not acceptable to bring private destinies to the Parliament; they belong to be handled in court. This one-sided view cuts off the possibility to give rape victims a face, which in turn could contribute to reduce the social stigma attached to rape victims and their families.

The second issue concerns a question of payment of MPs and journalist, which appeared after the event. These articles represent a split view of TAMWA. Three of the articles focus on TAMWA's good intentions by paying the MPs in order to convince them to attend in the struggle against sexual harassment and rape. It is also foregrounded that TAMWA is willing to sleep in tents to economize, which implies that TAMWA members sacrifice own comfort to the campaign. However, the issue of payment also raises harsh critique in other articles in which TAMWA is condemned for discriminating against debate members (see example below). Partly, TAMWA is criticized for paying the MPs allowances while the journalists had to sleep in tents, and partly for paying some journalists while others didn't get paid. The complaints come from both MPs speaking on behalf of the journalists and journalists themselves:

\section{HEKO 29/7/97, by correspondent in Dodoma MPS CONDEMN TAMWA FOR DESPISING THE JOURNALISTS}

Several members of the parliament have complained against the Tanzania Media Women Association (TAMWA) for paying them big allowances in the women debate and forgot the journalists, even the ones they came with from Dar es Salaam. .... Honorable Juma Akukweti said that keeping people [journalists] in tents while they had preserved money for paying the MPs was not wise and does not confirm to Tanzanian customs and traditions. He said, Tanzanians are used to cooperating in everything when they are in trouble or harmony.

The articles are written from the journalists' point of view who are part of the conflict, and might be said to signalize the journalists (authors) opinions. This is reflected in foregrounding accusation that are based upon the journalists' own observations or supported by MPs statements as in the example above. Choices of negative laden vocabulary confirm the negative image of TAMWA, such as condemn and despising. Alternatively, it could have stressed that the journalists attending the meeting traveled and ate on TAMWA's expense and had the opportunity to sleep in tents for free rather than complaining of what they didn't get. With all respect, it is the journalists'/media's job to cover important events and issues in society. 
Overall, the tone is changing and TAMWA put in a negative light by portraying their organizing methods on two different issues directly or indirectly as emotional, unfair, improper, immoral, dishonest, and disrespectful that needs to be condemned. A possible ideological implication is re-enforcing a prevailing attitude that women are too emotional and not fit as organizers or social coordinators of issues of public concern. In a wider meaning such a definition of women or femininity could restrict women's participation in politics, decision-making, and recourse allocation and thereby in development of the country as a whole.

\section{Castration, Hanging, Injection or Shot to Death}

How to deal with the increasing incidents of rape, sodomy, and defilement against women and children is the main theme in ten articles. Most of the articles are in form of news reports; repeating suggestions, views and opinions. The news discourse has shifted to portray MPs as the agents who want to take action against these "evils", while TAMWA figures more in the background. However, some newspapers choose to blow up certain views or stress an angle that are eye catching out of commercial motives rather than informative or educational purposes.

About half of the articles foreground serious propositions that were presented in the debate on behalf of TAMWA, and thereby indirectly support TAMWA's ideas. These measures include amending existing laws, a proposal on special courts for sex offenders, the establishment of a human right committee, and to change the police form (PF3) claimed to be inadequate to prove rape, sodomy, and defilement. The other half of the articles stresses lighthearted suggestions from the MPs that signalize that they don't take the debate seriously. This is reflected in headings and leads, which can be illustrated by the following title: RAPING: WHICH PUNISHMENT IS SUITABLE - CASTRATION, INJECTION OR DEATH BY A GUN? Members of Parliament are still mediating on this issue (Mtanzania, July 30 1997). Suggestions include hanging or shooting the "culprit" in public, injection to weaken sexual power, separate apartments in jail so the rapists can "rape themselves". While these kinds of statements make big headlines in the newspapers they are not very useful for the debate. There are at least two possible implications involved. First, it makes a critical issue that should be treated with care and respect into a laughing matter, which might also indicate that the MPs are not taking the organizers of the debate in a serious manner (read women). Second, more important arguments and solutions to the problem of sexual harassment and rape get less attention by the newspapers and possibly by their readers.

Male sources are now outnumbering female sources, and there is a tendency to forefront a male source before a female source. Both tendencies can partly be explained by that the majority of the MPs and Ministers are men, and partly by valuing a man's opinion before a woman's opinion. Still, female MPs are represented in almost every article and in some articles they 'compete' with their male peers. A positive implication to draw from this is that women to a certain degree are portrayed as subjects and to hold important posts as MPs, who are enacting upon events to change the conditions of women and children.

\section{Women in Miniskirt and Mentally Ill Men}

While law and court procedures is an attempt to combat rape, sodomy, and defilement in society moral decay is a recurrent theme introduced to explain causes to the increase 
of these offenses. It corresponds to the journalistic category wHY is it happening, which is usually backgrounded in news reports if taken in into consideration at all. However, in most of the articles discussed in the previous section it is made one or more attempts to explain causes to the increase of rape, sodomy, and defilement. In addition, moral decay is also the main topic in four articles. Recurrent issues are women's dressing, influence of television and western culture, and mental illness. Blames are directed against "sexually starved men" for raping women and as "a strange mental illness that drives a man to assault a toddler the size of his sexual organ". TV is repeatedly blamed to teach the youths a western culture and lifestyle, for instance by showing "half-naked women dancing in seductive ways " that can cause to raise men's emotions and lead to rape. However, attacks against women in mini-skirts and "certain behavior" are made into a major issue that outdo the other explanations framed within the broader framework of moral decay.

In total, ten articles touch upon the question of women's dressing. When treated as a sub theme the articles mostly report upon MPs divergent opinions. Some claiming that the way some women dress arises men's emotions and lead to rape. Others deny that this is a reason or should be used as an excuse for rape, defend women's right to dress as they wish, and that men have to cultivate self-discipline in order to get respected. The issue of dressing is a good example on how the movement from socialist to capitalist principles creates conflicts between traditional and modern values, and how the media becomes an arena for contestation where prevailing definitions of gender are being contested.

The articles taking up moral decay as the main topic forefront a one-sided critique against women in mini dresses as illustrated in the example below. TAMWA is the main news actor in two of these articles in which the organization is criticized for defending women's freedom to dress as they wish. The editor (male) in the example below supports TAMWA's efforts and fight against rape and sexual harassment as can be seen in the lead paragraph. However, a feminist discourse is undercut by focusing on women (victims) as the main source to the problem of rape and sexual harassment. The author makes explicitly his views, which might mold values, norms, and beliefs in the interest of a traditional perception of women and femininity. TAMWA is seen to go against Tanzanian moral and culture, and thereby contribute to moral decay in the society (fatal effects).

\section{HEKO 11/8/97 By the editor}

\section{TAMWA SHOULD NOT SWERVE FROM TANZANIAN MORALS}

The Tanzania Media Women Association (TAMWA) has come up on the front line in the struggle for women's rights. ... The struggle for children's rights, the female child's right to education, sexual harassment within the Tanzanian society are the efforts that have given TAMWA very high respect.... According to the moralities of our country, we did not expect women who are required to awake the society and to stand firm, like TAMWA, defending dresses that are not respectful in our society. ... The event that was reported upon in the media yesterday about mocking of a woman in such dressing is enough testimony that the society does not accept it. 
The last statement in the example above refers to a news report from the day before: $\mathbf{A}$ WOMAN MOCKED IN DAR FOR PUTTING ON A SHORT DRESS (paper unknown 10/8/97). The event is based upon a chain of actions. A woman had put on a very short dress (x), and after being groaned and mocked at with insults and accusations by a group of people in the city (y), she ran around to by "kitenge" to cover up and disappeared in a taxi (z). In other words, the woman is both subject and victim of other people's actions, which she has brought upon herself due to her own selfishness, and the consequences of her actions are fatal. However, the story doesn't stop here: "When people were rounding her (the woman mocked), some were heard singing a song, some of the words were TAMWA, TAMWA, the words were not clear ...". Unlike the editor, the journalist makes no explicit judgments, but link the singing to the TAMWA Symposium and leaves a gap to be filled in by the readers. Following the structural logic of the text it explains and naturalizes a sequence of events, which implies that dressing up in miniskirts is morally wrong and the society will not accept such behavior. Embedded in the discourse is also that TAMWA is wrong in supporting such immoral acts. This is backed up by a statement in the last paragraph in which the journalist points to two lawyers who claim, "that within the law there is a notion of being in a dignity situation and that all shameful practices should be groaned at".

There are several ideological implications involved. First, the overall message in all four articles focusing on moral decay is that if you break with the dominant cultural codes you will face the consequences both as individuals and organizations. Second, both the direct and indirect transmission of the news favors a view that moral decay is a major cause to the increase of rape, sodomy and defilement, and thereby fail to grasp underlying gender-based power relations, cultural attitudes, and social structure. Third, by focusing on women only the problem is localized to women (the victims), who are seen to have brought such acts upon themselves. This biased focus not only frees men from the responsibility, but also avoids pinpointing underlying gender-based power relations. Both the authors and the sources in the four articles discussed here are males and could therefore be said to signal a male attitude that might favor a specific ideological perspective geared towards men's interests, which reproduces and legitimates men's power. In turn, such an ideological perspective might govern news gathering routines, interpretation of sources and other texts, and description of news events.

\section{Conclusion}

The discourse analysis reveals that fighting for gender transformation is a slippery road with lots of turns and potholes involving both opportunities and risks for a woman's movement and its NGO's spearheading the struggle. The articles focusing upon WHAT the debate is about represent the most positive position for TAMWA and opens up for a feminist discourse (I). It is stressed that TAMWA is in the frontline of woman's struggle for liberation, and the articles express directly or indirectly support for TAMWA's efforts. The newspapers draws upon TAMWA as an important source and discourse, which is significant not only for the approval of TAMWA's objectives and ideas, but also represents a vital moment in a woman's movement in challenging dominant discourse of gender. An important dimension in the news discourse is that women are portrayed to be the agent carrying out the event, driven by a motivation for the social good intending to improve the conditions of women and children. The discourse contests the gender dichotomy prevailing in society by portraying women as actors in the public sphere, as social coordinators defined in terms of role categories aligned with culture. Implicit the 
news discourse embodies ideas and values that challenge traditional beliefs about women as subordinate, emotional and unable to participate in public debate and decision-making. In turn, this can have a positive effect on the inclusion of women in decision making, coordination and resource allocation, and thereby channel development in the interests of women and children. At the same time, grassroots women have a strictly limited voice and positioned as victims of gender violence, rape, and sexual harassment. In a covert manner it might be said that there is a distinction between woman activists (and female MPs) on one side, and ordinary women on the other. This positioning is probably partly a result of news conventions attaching news value to elite groups before ordinary people. Nevertheless, the underlying distinction could affect the ways in which individuals take up positions inscribed in the news discourse, and thereby limit the effect of alternative gender representations.

In spite of the news discourse being rather coherent in supporting TAMWA's objectives with the Symposium the organization 'looses' control as the event evolves. TAMWA's ability to organize is disputed on several issues in articles concerned with HOW the event was conducted (II). As news actor and agent TAMWA is now competing with MPs, and the majority of sources are males as are the journalists. Members of Parliament takes over as the main news actor/agent in the articles concerned with HOw to deal with the increasing incidents of rape, sodomy, and defilement (III). Male sources are outnumbering female sources. Compared to the articles in the first category a feminist discourse is now backgrounded in favor of a commercial discourse turning the issue into a show of punishment methods. In the last category wHY is it happening and wном to blame TAMWA seems to have lost all influence over the debate, which turns into a question of moral decay in particular blaming women themselves. The strong focus upon mini-skirts and to a certain degree TV and western influence takes the attention away from deeper social and cultural explanations. In sum, the analysis show that the interaction between TAMWA, MPs and journalists representing different institutional and personal interests plays an important role in the development of a woman's movement. In particular, the media's interpretations have wider implications for the formation of a woman movement's identity. It also shows that the struggle of meaning takes place within existing frames of power relations in society in which the access and power to engage in the process of reality defining is reflected along power lines in society. The main impression is that these articles facilitate a negative image that could cause TAMWA's basic objectives and ideas to suffer.

The power of discourse is visible in defining what is a social problem. Among the various themes that were presented at the Symposium one specific issue is foregrounded in the news discourse; rape, sodomy, and defilement. Other important themes and issues that were introduced during the Symposium get little attention, such as wife battering, land and inheritance rights, social and cultural norms discriminating against women and girls. This choice might be interpreted as being geared towards commercial interests in which women have become objects of sensational news reporting (sex and violence). Moreover, the news discourse prescribes that rape is an issue that should be understood as a human right issue within a liberal feminist framework, which undercuts the importance of an alternative framework of interpretation scrutinizing underlying gender-based power relations and the meaning of gender. The power of discourse also lies in writing off TAMWA's plan to bring private testimonies as improper without taking into consideration of what could be gained. Last, but not at least the discourse legitimate the view that moral decay and deviant acts, such as mini-dresses, TV-influence, and mental illness 
are major explanations for the increase of rape, sodomy, and defilement. Such explanations isolate the case of raping, sodomy, and defilement from the rest of the society; like cancerous tumor that must be removed. The medicine prescribed is abandoning Western culture and television, and going back to the original African culture. Hence, the possibility that sexual harassment and abuse is a question of gender and power relations is eliminated and thereby the topic can be discussed without being a threat to men and their position. Blaming women in short dresses, television and western influence, and mentally ill men become superficial explanations for the increase and combat of rape, defilement and sodomy. In the debate there has not been presented any evidence that women in short dresses are more likely to be raped than women who dress according to Tanzania customs. Also, there is no indication that rape is more widespread in areas where the exposure of television is rather high than in areas where it rarely exists. All in all, the investigations for explanations have to go deeper into problems in society, and social and cultural practices and attitudes that naturalizes a male dominated culture and prestige structure.

The overall implication for gender might be of both empowering and disempowering character. Gender is constructed and reconstructed through various and sometimes contradicting ideas, values and definitions of femininity, which support a feminist post-structuralist view of the construction of gender as a discursive construct. Women are portrayed as both fit and unfit as social coordinators, as both active subjects enacting upon events and victims of other people's actions, as both freedom fighters and immoral temptations. The news discourse carries multiple ideological positions or gender positioning, which in turn place the individual reader in heterogeneous, overlapping, and competing ways.

\section{Notes}

1. This paper is based upon parts of my work on my doctoral thesis: Gender, Media and Development: The role of the Media in the Cultural Struggle of gender transformation in Tanzania.

2. The gender dichotomy is based upon a well-known anthropological dichotomy as suggested by Ortner and Whitehead (1981), who operates with the following oppositions claimed to recur cross culturally: Nature vs. culture, domestic vs. public, self interest vs. social good.

3. This statement is based on a survey conducted by the author of 14 newspapers in Dar es Salaam during two weeks of September 1997.

\section{References}

Allen, Robert C. (1992) Channels of Discourse, Reassembled, Routledge, London, UK.

Ang I. \& Hermes J.(1996) "Gender and/in Media Consumption", in Curran J. \& Gurevitch (eds.): Mass Media and Society, St. Martin's press Inc., NY, USA.

Camauer, Leonor (2001) Konskonstruktion, representation och den feministiska mediekritiken, paper presented at The $15^{\text {th }}$ Nordic Conference on Media and Communication Research, Island

Chatman, Seymour (1983) Story and Discourse: Narrative Structure in Fiction and Film, Cornell University Press N.Y.

Gamson, William G. (1995) "Constructing Social Protest”, in Johnston \& Klandermans (eds.): Social Movements and Culture, UCL Press, London.

Kozloff, Sarah (1992) "Narrative Theory and Television", in Allen (ed.): Channels of Discourse, Reassembled, Routledge London UK.

Lange, Wallevik, Kiondo (2000) Civil Society in Tanzania, Commissioned Report, Chr. Michelsen Institute Norway.

Melkote, Srinivas (1991) Communication for Development in the Third World. Theory and practice, Sage London. 
Mtambalike, Pili (1996) "Newspaper Reporting and Gender", in Mbiliny/Omari (eds.): Gender Relations and Women's Images in the Media, Dar es Salaam University Press, Dar es Salaam, Tanzania, 1996.

Ortner, Sherry B \& Whitehead, Harriet (eds.) Sexual Meanings; the cultural construction of gender and sexuality, Cambridge University Press, 1981.

Taylor \& Whittier (1995) “Analytical Approaches to Social Movement Culture: The Culture of the Women's Movement", in Johnston \& Klandermans (eds.): Social Movements and Culture, UCL Press, London.

Van Dijk, Teun A. (1991) "The interdisciplinary study of news as discourse", in Jensen \& Jankowski (eds.): A handbook of Qualitative Methodologies for Mass Communication Research, Routledge, London, New York

White, Mimi (1992) "Ideological Analysis and Television", in Allen (ed.): Channels of Discourse, Reassembled, Routledge London UK.

Zoonen, L. van (1994) Feminist Media Studies, Sage Publications Ltd., London. 